Viso - Cadernos de estética aplicada Revista eletrônica de estética

ISSN 1981-4062

$N^{\circ} 10$, jan-dez/2011

http://www.revistaviso.com.br/

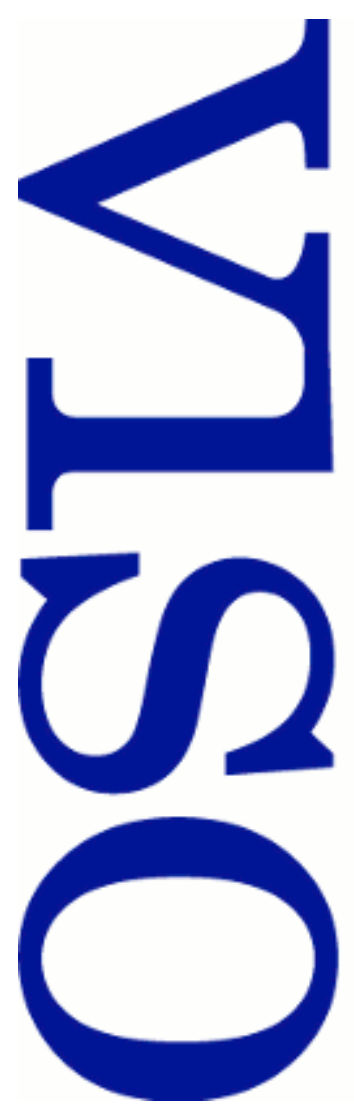

\title{
Sobre a possibilidade de se estabelecer um paralelo entre canção e prosa Thiago Rodrigues
}




\section{RESUMO}

Sobre a possibilidade de se estabelecer um paralelo entre canção e prosa Objetiva-se com este estudo perscrutar as possibilidades de se estabelecer uma relação entre a canção popular, tal como definida por Luiz Tatit, e a concepção sartriana de prosa como elemento de comunicação, e, portanto, como instrumento político, sem com isso afirmar uma concepção instrumental da arte. Neste percurso recorrer-se-á a um fenômeno da musica popular brasileira conhecido como rap. Deste modo pretende-se lançar luz sobre as questões levantadas.

Palavras-chave: canção popular - prosa - música popular - rap

\section{ABSTRACT}

About the Possibility of Establishing a Parallel between Folk Song and Prose

The objective of this study is to scrutinize the possibilities of establishing a relationship between the popular song, as defined by Luiz Tatit and Sartrean conception of prose as an element of communication, and therefore as a political instrument, without thereby asserting a design instrumental art. In this way will draw to a phenomenon of Brazilian popular music known as rap. Thus it is intended to shed light about the issues raised.

Keywords: popular song - prose - popular music - rap 


\section{RODRIGUES, T. "Sobre a possibilidade de se estabelecer um paralelo entre canção e prosa". In: Viso: Cadernos de estética aplicada, v. V, n. 10 (2011), pp. 85-94.}

DOI: $10.22409 / 1981-4062 / v 10 i / 113$

Aprovado: 28.03.2012. Publicado: 19.04.2012.

(C) 2012 Thiago Rodrigues. Esse documento é distribuído nos termos da licença Creative Commons Atribuição-NãoComercial 4.0 Internacional (CC-BY-NC), que permite, exceto para fins comerciais, copiar e redistribuir o material em qualquer formato ou meio, bem como remixá-lo, transformá-lo ou criar a partir dele, desde que seja dado o devido crédito e indicada a licença sob a qual ele foi originalmente publicado.

Licença: http://creativecommons.org/licenses/by-nc/4.0/deed.pt_BR

Accepted: 28.03.2012. Published: 19.04.2012.

(C) 2012 Thiago Rodrigues. This document is distributed under the terms of a Creative Commons Attribution-NonCommercial 4.0 International license (CC-BY-NC) which allows, except for commercial purposes, to copy and redistribute the material in any medium or format and to remix, transform, and build upon the material, provided the original work is properly cited and states its license.

License: http://creativecommons.org/licenses/by-nc/4.0/ 


\section{Mas o Rap também é canção?}

A história da canção popular brasileira conheceu na passagem do século XX para o século XXI o surgimento de um gênero musical, o rap, que para alguns estudiosos não pode ser considerado como canção, ao menos tal como esta se desenvolveu historicamente. Parece este o caso do musicólogo e crítico Zuza Homem de Melo que, em diversos depoimentos ${ }^{1}$, questiona a classificação do rap como representante da canção pois, neste gênero, um dos elementos fundamentais para caracterizar a canção, a saber, a melodia, não estaria presente.

É notória também a tese defendida por Luiz Tatit, no que concerne ao tema, de que o rap é um gênero legítimo dentro da tradição do cancioneiro brasileiro. Mas por que este descompasso? E o que Tatit entende por canção?

Um pressuposto fundamental para se pensar a canção, segundo Tatit, é a tensão entre a forma musical e a força entoativa. ${ }^{2}$ No entanto, mesmo reconhecendo o caráter prosaico ${ }^{3}$ da canção, não são poucos os compositores, tanto eruditos quanto populares, que buscam lançar suas composições para instâncias mais "artísticas", afastando-as de sua função comunicativa. É só pensarmos nos Lieder românticos, por exemplo, ou então em diversas composições da Bossa Nova nas quais a mensagem, nas palavras do próprio Tatit, é deixada em segundo plano. Existem também as composições que se caracterizam no sentido oposto: se, por um lado, há compositores que ressaltam em suas composições a forma musical, deixando em segundo plano a força entoativa e, desse modo, a função comunicativa da canção, por outro lado, existem composições que pretendem exaltar a mensagem linguística, como é o caso do rap.

Tatit deixa bastante claro, no entanto, que a característica fundamental da canção é justamente a junção entre música (forma musical) e palavra (força entoativa). Sendo assim, mesmo quando se privilegia a palavra ou se destaca a forma musical, ambas (música e palavra) estão presentes na canção.

Cabe citar Tatit quando este descreve a especificidade do rap. A citação, embora um pouco longa, se justifica pois quase todo nosso comentário posterior partirá dela:

A passagem do século $\mathrm{XX}$ ao $\mathrm{XXI}$ foi marcada, no terreno popular, pela explosão do rap, gênero bastante comprometido com a mensagem linguística, e que, portanto, não pode prescindir dos contornos rítmico-melódicos que dão expressividade à letra. Aqui, ao invés, não contamos com precisão no âmbito da sonoridade e muito menos com a escrita que sempre garantiu o registro da forma, por mais complexa que fosse, na música culta. Os autores se apegam antes de tudo a um modo de dizer, ao próprio teor verbal de suas frases e, se aproveitam algumas recorrências musicais, distribuem-nas pelo plano da expressão da letra, gerando rimas e assonâncias que colaboram na memorização dos longos discursos. O resto é força entoativa quase pura que pouco concede aos ritos musicais de estabilização sonora. ${ }^{4}$ 
Neste sentido, Zuza Homem de Melo não teria razão ao questionar a classificação do rap enquanto canção? No registro de Tatit, não, pois, embora "comprometido com a mensagem lingüística", o rap "não pode prescindir dos contornos rítmico-melódicos que dão expressividade à letra", o que significa que a forma canção exige a junção entre palavra e música para existir. É por isso que Tatit afirma que "[...] embora se trate do gênero [o rap] que mais tirou proveito da força entoativa, nunca o rap deixou de lado os padrões mínimos da estabilização musical". ${ }^{5}$ Ou seja, palavra e música fazem parte de um todo, no qual a relação entre entoação e forma musical determinarão a função comunicativa da canção, mesmo que se privilegie a mensagem linguística ou a forma musical. É justamente a junção desses dois âmbitos que determinará a forma canção. Vejamos um pouco mais de perto como se dá essa relação para o autor.

Esta tensão caracteriza a relação entre a forma musical e a força entoativa, desvelandose como uma via de mão dupla, ou seja, se estabelece em uma relação "proporcional". Tomemos as duas "situações-limite" descritas, os Lieder e o rap, como exemplo em nossa análise. No caso dos Lieder, "desaparecem os vestígios da entoação diante das exigências de uma forma musical pura que se basta", ${ }^{6}$ levando, no limite, à saturação da forma musical. No entanto, é neste momento que a própria estrutura da canção parece exigir o restabelecimento de seu caráter entoativo, evitando o dilaceramento de sua própria estrutura. Quando isto não ocorre, como no caso do vocalize, recurso bastante recorrente na história da canção brasileira, a voz passa a funcionar única e exclusivamente como um instrumento, o que descaracterizaria a canção.

Um exemplo bastante significativo desta quase saturação da forma musical se dá na Bossa Nova que, no entanto, para evitar dissolver a forma canção e recair na música exclusivamente instrumental, atenua seus recursos meramente técnicos em favor da expressividade da maneira de se dizer cada frase da letra, impedindo assim a saturação musical e permanecendo no universo da canção. ${ }^{7}$ Isso evidencia aquilo que chamamos de via de mão dupla, ou seja: quanto mais nos encaminhamos para a forma musical pura, mais nos distanciamos da força entoativa e de sua função comunicativa.

O contrário também pode acontecer, isto é, o recurso à função comunicativa pode ameaçar o aspecto musical da canção, como parece ser o caso do rap. Mas, também aqui, a desconstrução da forma canção é evitada - caso contrário, recairíamos no discurso do comício, por exemplo, e a forma canção se esvaneceria. Desse modo, "os próprios rappers [...] não deixam a forma musical se extinguir, pois [...] providenciam [...] o restabelecimento de outras diretrizes musicais, como a grade rítmica e as recorrências sonoras dos fonemas". 8

Assim, tal como sintetiza Tatit:

[...] há correspondências evidentes entre as oscilações tensivas da forma musical e da força entoativa. A saturação da forma pode, em muitos casos, corresponder à extinção 
da força. E vice-versa. O estabelecimento da forma musical,[...] reproduz, de certo modo, a atenuação da força entoativa $[\ldots]^{9}{ }^{9}$

A concepção de Tatit acerca do rap enquanto legítimo representante da canção popular brasileira, no qual a mensagem ganha destaque e, por conseguinte, a função comunicativa da canção se sobrepõe à sua forma musical, é expressa pelo autor em diversas passagens. Consideremos o seguinte depoimento, no qual esse caráter se torna mais evidente:

O rap, neutralizando a melodia, faz com que a gente preste atenção à mensagem, vira quase fala pura, como se fosse a origem da canção, que é a fala pura [...] a canção pura é o rap, pois tem o essencial da canção que é a entoação. Desse modo, por ficar muito próximo da fala, fica mais fácil de passar a mensagem. ${ }^{10}$

É justamente este o ponto que nos interessa aqui. Sendo assim, não mais acompanharemos as instigantes análises de Tatit e passaremos a outra etapa de nossa breve reflexão.

\section{Mas o rap é prosa?}

Sartre escreve seu famoso ensaio acerca da pergunta fundamental sobre o que é a literatura como resposta a uma série de críticas que the foram dirigidas por defender a literatura engajada. Uma das primeiras objeções que Sartre enfrenta é se o filósofo existencialista não estaria repetindo o erro dos pintores soviéticos. Ou seja, não estaria o autor instrumentalizando a arte? Um pressuposto aqui é a identificação entre a literatura e as "outras artes". ${ }^{11}$ Daí a pergunta: Você quer engajar as artes?

Ao que responde o autor: 'Não, nós não queremos 'engajar também' a pintura, a escultura e a música, pelo menos não da mesma maneira. $E$ por que haveríamos de querer, como se todas as artes se equivalessem?"12 Então, Sartre chama atenção para a especificidade da literatura e, em especial, da prosa.

Assim, se queremos compreender como se dá o engajamento da música segundo o filósofo francês, precisamos primeiramente entender o que distingue a literatura das "outras artes".

Tomemos como fio condutor para esta breve explanação a distinção feita pelo filósofo logo no inicio do referido ensaio, a saber, entre o que ele chama de "palavra opaca", isto é, a poesia, e "palavra translúcida", ou seja, a prosa.

Como foi dito acima, por "palavra opaca" o autor entende a poesia, que é o mesmo que dizer que a poesia se realiza como positividade pura. Mas o que significa afinal dizer que a poesia é positividade pura? Significa que a palavra, na poesia, não representa algo 
para além dela mesma, isto é, para o poeta, segundo Sartre, "as palavras são como coisas". ${ }^{13}$ Essa concepção fica mais clara se compreendermos o que o autor entende por "palavra translúcida".

A prosa ou "palavra translúcida" tem lugar quando a linguagem ganha um caráter, ao menos em certa medida, instrumental. Assim, se para o poeta a palavra aparece como coisa, como positividade pura, para o prosador a palavra aparece como pura translucidez, como signo, como uma ferramenta capaz de dizer alguma coisa. Desse modo, o escritor (prosador) lida com significados e, portanto, a palavra é sempre um meio para se alcançar algo para além dela mesma. O filósofo chega a afirmar que "a prosa é utilitária por essência: [assim] eu definiria de bom grado o prosador como um homem que se serve das palavras". ${ }^{14}$ Ou seja, se a finalidade da linguagem é comunicar algo para alguém, a prosa é necessariamente engajada. Por quê? Se a prosa sempre comunica algo, e se o homem está condenado a ser livre, como defende o filósofo, quando se escreve, se escolhe; e, ao escolher, o homem escolhe por ele e por todos os outros, o homem elege valores e se engaja em algo, mesmo que faça isso de forma "alienada". Consequentemente, a prosa carrega sempre um viés ético. ${ }^{15}$

No entanto, embora a maior parte dos comentadores defenda que Sartre realiza uma instrumentalização da obra de arte $^{16}$, nossa leitura se adequa à concepção defendida por Franklin Leopoldo e Silva em Ética e literatura em Sartre: Ensaios introdutórios. ${ }^{17}$ Segundo o comentador, há uma relação de interdependência entre o âmbito teórico e o âmbito estético da prosa, de modo que Sartre não negligencia a prosa enquanto obra de arte, o que se evidencia em passagens como esta: "Ninguém é escritor por haver decidido dizer certas coisas, mas por haver decidido dizê-las de determinado modo. E o estilo decerto é o que determina o valor da prosa". ${ }^{18}$ Ou então:

Lembro, com efeito, que na "literatura engajada", o engajamento não pode, em nenhum caso, fazer esquecer a literatura e que nossa preocupação deve ser a de servir à literatura infundindo-lhe sangue novo, assim como servir à coletividade tentando the oferecer a literatura que the convém.

Mas isso ainda não responde a pergunta acerca do engajamento das "outras artes". É que, para Sartre, a pintura se assemelha à poesia, na medida em que também a pintura, assim como a música, não lida com signos. Isso soa estranho fora do registro em que o filósofo desenvolve seu pensamento. Na realidade, dizer que a pintura não trabalha com signos é o mesmo que dizer que ela é positividade pura, e que, portanto, não remete a nada, não é um meio para se alcançar alguma outra coisa. Como exemplifica o autor, quando Tintoretto pinta um rasgo amarelo no céu sobre o Gólgota, ele não busca significar ou provocar a angústia, como se o amarelo representasse a angústia, mas sim, "ele é angústia e céu amarelo ao mesmo tempo". ${ }^{19}$ É angústia feita coisa.

Essa concepção fica mais clara no caso da música. Qual é o significado de uma melodia? O que ela diz? O significado de uma melodia "não é nada mais que a própria 
melodia, ao contrário das ideias [que é o caso da prosa] que podem ser traduzidas adequadamente de diversas maneiras". ${ }^{20}$ Análoga à música, na pintura, qual é o significado do angustiante amarelo do céu de Tintoretto? Como traduzir adequadamente essa angústia? Ou seja, o amarelo é a própria angústia feita coisa, assim como uma melodia triste é a própria tristeza materializada.

\section{Se "Caetano" ${ }^{21}$ é poesia, então o rap não seria prosa?}

Não nos interessa aqui o caso da música tomada em termos absolutos, mas sim o da canção. Desse modo, a pergunta - já clássica! - acerca da poesia na canção popular se justifica: a canção popular brasileira, tal como ela se constituiu historicamente, pode ser considerada como poesia? Essa pergunta guarda em seu bojo ao menos um preconceito, a saber, de que a poesia se configuraria como um âmbito mais nobre da produção artística do que a canção, o que pressupõe uma concepção hierarquizante. Ora, se entendemos essa aproximação com a poesia apenas como uma forma de "enobrecer" a canção, então o problema nos parece ocioso, pois a poesia por si só não é melhor nem pior que a canção. Trata-se apenas de outra forma de expressão artística. É como comparar um romance a um filme. O filme por si só não é melhor nem pior que o romance. Trata-se apenas de outra linguagem. Se pensarmos que a aproximação entre poesia e letra se refere à forma poética, ou seja, à palavra destinada ao texto impresso, então a questão parece mais supérflua ainda, pois é justamente o caráter entoativo da fala cantada que caracteriza a canção, ao menos no registro em que Tatit a define, tal como vimos anteriormente. Portanto, a canção não é poesia simplesmente porque não é feita para o papel (mesmo que se entenda que a poesia impressa também pressupõe a leitura em voz alta), e sim para a melodia.

Mas não nos interessa aqui discutir este problema dentro deste registro. No entanto, é preciso perscrutar, ao menos, se a palavra cantada, dentro da tradição do cancioneiro brasileiro, se aproxima mais daquilo que Sartre chama de "palavra opaca" ou da "palavra translúcida", do universo da poesia ou da prosa.

Vimos, com Tatit, que toda canção comunica, e que é a relação entre a forma musical e a força entoativa que determinará sua função comunicativa. Ficou patente também que, dentre os vários gêneros da música popular brasileira, o rap foi aquele que mais verticalizou esta relação, levando a função comunicativa da canção - ou como prefere Tatit "a mensagem" - às últimas consequências.

Assim, se o que caracteriza a prosa - ou se se preferir, a "palavra translúcida" -, para Sartre, é sua função comunicativa, pois a prosa sempre visa dizer algo a alguém, não seria pertinente perguntar se o rap não estaria para a canção assim como a prosa está para a literatura? Ou seja, não seria lícito aproximar a prosa ao rap, ao menos no que concerne à sua função comunicativa? Se assim é, não caberia a esse gênero então 
oferecer um espelho crítico ao homem, pois quando se $d^{22} z^{22}$ algo sempre se diz algo a alguém? E, se essa hipótese tem validade, isso não deveria ser feito de forma consciente?

O estatuto ontológico atribuído à palavra poética por Sartre, isto é, enquanto positividade pura, denota a diluição da função comunicativa da palavra. Desse modo, parece-nos lícito aproximar a falta de "fixação melódica do rap (justamente para destacar a mensagem)" ${ }^{\prime 23}$ à prosa, e, por outro lado, a melodização da palavra na maior parte da produção cancional (de Caetano Veloso) à "poesia". Mas é claro que a canção não é poesia no que tange à sua forma, e por que haveria de ser? Como diz também Tatit, a canção é, antes de tudo, entoação. No entanto, não nos parece artificial afirmar que a palavra na canção, dentro do registro proposto por Tatit, ora ganha um caráter "poético", pois destaca a forma musical, e, assim, afasta-se do registro puramente entoativo - o que, nas palavras do autor, significa que "a canção pura é o rap, pois tem o essencial da canção que é a entoação"; ${ }^{24}$ - e ora ganha um caráter "prosaico", pois enfoca o caráter figurativo da fala. É significativa a forma como Tatit também se refere a essa relação ao dizer que existem músicas para se entender (força entoativa) e músicas para se contemplar (forma musical), ${ }^{25}$ deixando bastante evidente o caráter comunicativo desta relação.

\footnotetext{
* Thiago Rodrigues é mestrando em filosofia pela UNIFESP.

${ }^{1}$ Dentre diversos depoimentos de Zuza Homem de Melo que explicitam essa posição podemos citar a comunicação proferida por Luiz Tatit intitulada O corpo coletivo e A morte da canção?, no qual, ao se contrapor a Tatit, Zuza Homem de Melo se posiciona contra a definição do rap enquanto canção.

${ }^{2}$ Visto que nosso intuito é menos nos aprofundarmos na teoria da canção defendida por Tatit e mais problematizar a relação entre a forma canção e sua "função" comunicativa, pautará esta etapa de nossa exposição um artigo publicado por Tatit na revista Estudos Semióticos, v. 6, n. 2, intitulado "Canção e oscilações tensivas".

${ }^{3} \mathrm{O}$ termo prosaico aqui alude àquilo que é relativo à prosa.

${ }^{4}$ TATIT, L. "Canção e oscilações tensivas". In: Estudos Semióticos, v. 6, n. 2, p. 14. (Grifo nosso).

${ }^{5}$ Ibidem, p. 15.

${ }^{6}$ Ibidem, p. 16.

${ }^{7}$ Ibidem.

${ }^{8}$ Ibidem.

${ }^{9}$ Ibidem, p. 17.

10 TATIT, L. O corpo coletivo e a morte da canção? Conferência proferida no CPFLCultura, Campinas/SP, em 01/04/2011. Registro em vídeo disponível na URL: http://vimeo.com/32227932. Acesso em 02/04/2012.
} 
${ }^{11}$ As aspas aqui buscam evidenciar que, segundo uma concepção fenomenológica, que é a grande influência de Sartre, cada manifestação artística guarda sua especificidade. No entanto, para o que buscamos, evidentemente, não nos aprofundaremos nessas especificidades.

${ }^{12}$ SARTRE, J.-. Que é a Literatura? Tradução de Carlos Felipe Moisés. São Paulo: Ática, 1989, p. 11.

${ }^{13}$ Ibidem, p. 13.

${ }^{14}$ Ibidem, p. 18.

${ }^{15}$ É importante ressaltar que essa distinção entre poesia e prosa não se dá de forma estanque, tal como apresentada aqui nesta breve exposição, o que significa que toda prosa é em certa medida "poética" e toda poesia é de certo modo prosaica, mesmo que em última instância sempre seja possível identificá-las.

${ }^{16}$ Ver BORHEIM, G. Sartre: Metafísica e existencialismo. São Paulo: Perspectiva, 2005, p. 283; PERDIGÃO, P. Existência e liberdade: Uma Introdução à filosofia de Sartre. Porto Alegre: L\&PM, 1995, p. 19.

${ }^{17}$ LEOPOLDO E SILVA, F. Ética e literatura em Sartre: Ensaios introdutórios. São Paulo: UNESP, 2004.

${ }^{18}$ SARTRE, J.-P. Op. cit., p. 22.

${ }^{19}$ SARTRE, J.-P. Op. cit., p. 11.

${ }^{20}$ Ibidem, p. 11.

${ }^{21}$ A referência a Caetano Veloso tem aqui caráter simbólico e busca representar um maior destaque da forma musical da canção em detrimento da força entoativa, lembrando que não existe canção fora da equação forma musical/força entoativa, segundo Tatit.

${ }^{22} \mathrm{O}$ "dizer" aqui é tomado no sentido em que Sartre se refere à prosa, ou seja, enquanto mediação entre as palavras e as coisas.

${ }^{23}$ TATIT, L. O corpo coletivo e a morte da canção? Op. cit.

${ }^{24}$ Ibidem.

${ }^{25}$ Ibidem. 